\title{
Potential Impact of Fluopyram on the Frequency of the D123E Mutation in Alternaria solani
}

\author{
Mitchell J. Bauske, S. K. R. Yellareddygari, and Neil C. Gudmestad, ${ }^{\dagger}$ Department of Plant Pathology, North Dakota State University, \\ Fargo 58105
}

\begin{abstract}
Succinate dehydrogenase-inhibiting (SDHI) fungicides have been widely applied in commercial potato (Solanum tuberosum L.) fields for the control of early blight, caused by Alternaria solani Sorauer. Fivepoint mutations on three AsSdh genes in A. solani have been identified as conferring resistance to SDHI fungicides. Recent work in our laboratory determined that $A$. solani isolates possessing the D123E mutation, or the substitution of aspartic acid for glutamic acid at position 123 in the $A s S d h D$ gene, were collected at successively higher frequencies throughout a 3-year survey. In total, $118 \mathrm{~A}$. solani isolates previously characterized as possessing the D123E mutation were evaluated in vitro for boscalid and fluopyram sensitivity. Over $80 \%$ of $A$. solani isolates with the D123E mutation evaluated were determined to be highly resistant to boscalid in vitro. However, effective concentration at which the fungal growth is inhibited by $50 \%$ values of isolates with the D123E mutation to fluopyram, ranging from 0.2 to $3 \mu \mathrm{g} / \mathrm{ml}$, were sensitive and only slightly higher than those of baseline isolates to fluopyram, which ranged from 0.1 to $0.6 \mu \mathrm{g} / \mathrm{ml}$. Five $A$. solani isolates with the D123E mutation were further evaluated in vivo for percent disease control obtained from

boscalid and fluopyram compared with two wild-type isolates, three isolates possessing the F129L mutation, two isolates possessing the H134R mutation, two isolates possessing the H133R mutation, and one isolate with the H278R mutation. Relative area under the dose response curve values for boscalid and fluopyram were significantly lower for all five D123E-mutant isolates, demonstrating reduced disease control in vivo. In field trials, the frequency of $A$. solani isolates with the D123E mutation recovered from treatments receiving an in-furrow application of fluopyram ranged from 5 to $37 \%$, which was significantly higher compared with treatments receiving foliar applications of standard protectants, in which the frequency of the D123E mutation in isolates ranged from 0 to $2.5 \%$. Results suggest that $A$. solani isolates possessing the D123E mutation have a selective advantage under the application of fluopyram compared with SDHI-sensitive isolates, as well as isolates possessing other mutations conferring SDHI resistance. These data illustrate the importance of implementing fungicide resistance management strategies and cautions the use of fluopyram for in-furrow applications that target other pathogens of potato.
\end{abstract}

Alternaria solani Sorauer, which causes early blight of potato (Solanum tuberosum L.), creates characteristic dark-brown to black lesions with a concentric ring pattern on senescing leaves. Early blight is a ubiquitous disease and particularly problematic on potato crops grown under irrigation and during periods of heavy dew (Rotem 1994). In addition to inducing premature defoliation of infected potato plants, resulting in tuber yield reduction, $A$. solani can also cause a type of dry rot on tubers which decreases quality (Nnodu et al. 1982). Because the majority of commercial potato cultivars are susceptible to early blight, the application of foliar fungicides over the course of the growing season is required to achieve sufficient control (Gudmestad et al. 2013; Yellareddygari et al. 2016). Standard protectants such as chlorothalonil and mancozeb are perhaps the most frequently applied fungicides for early blight management but are insufficient under high inoculum pressure and conducive environmental conditions (Fonseka and Gudmestad 2016; Yellareddygari et al. 2016). As a result, the application of locally systemic and translaminar fungicides such as quinone outside inhibitors (QoI) and succinate dehydrogenase inhibitors (SDHI) may be necessary to keep disease levels below economic thresholds (Yellareddygari et al. 2016). QoI fungicides were used successfully following their introduction in 1999 but resistance was detected in North Dakota and Nebraska by 2001 (Pasche et al. 2004, 2005) and determined to be prevalent throughout much of the United States by 2006 (Pasche and Gudmestad 2008). Reduced sensitivity in A. solani results from the F129L mutation (the substitution of phenylalanine with leucine at position 129 in $c y t b$ ) (Pasche et al. 2005), which conveys up to a 15 -fold reduction in sensitivity to QoI fungicides.

${ }^{\dagger}$ Corresponding author: N. C. Gudmestad; E-mail: neil.gudmestad@ ndsu.edu

Financial support was provided by Bayer CropScience.

Accepted for publication 17 October 2017.

() 2018 The American Phytopathological Society
The target site of SDHI fungicides is mitochondrial complex II at either the succinate ubiquinone reductase or succinate dehydrogenase complex, which is a functional part of the mitochondrial electron transport chain (Avenot and Michailides 2010; Sierotzki and Scalliet 2013). The SDHI fungicide boscalid was registered in the United States for use on potato in 2005 and initially provided excellent early blight control (Fairchild et al. 2013; Gudmestad et al. 2013; Pasche and Gudmestad 2008). Unfortunately, resistance to boscalid has developed in a number of different host-pathogen systems, including A. alternata in pistachio (Avenot and Michailides 2007), Botrytis cinerea in several crops (Bardas et al. 2010; Leroch et al. 2011; Myresiotis et al. 2008; Yin et al. 2011), Corynespora cassiicola in cucumber (Ishii et al. 2011; Miyamoto et al. 2009), Didymella bryoniae in cucurbits (Avenot et al. 2012), Monilinia fructicola in peach (Amiri et al. 2010), and Venturia inaequalis in apple (Toffolatti et al. 2016). Boscalid resistance was first detected in A. solani in field isolates collected in 2009 and 2010 from Idaho (Wharton et al. 2012) and subsequently found to be prevalent throughout a number of states, including North Dakota, Minnesota, Nebraska, and Texas, in 2010 and 2011 (Gudmestad et al. 2013). Five-point mutations on three $A s S d h$ genes previously have been characterized to independently confer resistance to SDHI fungicides (Mallik et al. 2014). Two-point mutations occurring on the $A s S d h B$ gene leading to an exchanges from histidine to tyrosine (H278Y) or arginine (H278R) at codon 278 convey moderate to high levels of resistance to boscalid and penthiopyrad. An exchange from histidine to arginine (H134R) at codon 134 on the AsSdhC gene has been shown to confer very high boscalid and penthiopyrad resistance. Two additional exchanges from histidine to arginine (H133R) at codon 133 and aspartic acid to glutamic acid (D123E) at codon 123 on the $A s S d h D$ gene have also been shown to convey high resistance levels to boscalid and penthiopyrad (Mallik et al. 2014). At the time of these investigations, it appeared that none of the five SDHI resistance mutations affected the sensitivity of $A$. solani to fluopyram (Fairchild et al. 2013; Gudmestad et al. 2013; Mallik et al. 2014; Miles et al. 2014).

The SDHI fungicide fluopyram was registered for use on potato in 2012 and became a reliable alternative to QoI fungicides as well as 
other SDHI. This is largely due to the demonstrated lack of cross resistance between boscalid and fluopyram among $A$. solani isolates that have developed resistance to boscalid (Fairchild et al. 2013; Gudmestad et al. 2013; Mallik et al. 2014). Although the lack of cross resistance between fluopyram and boscalid in other fungi has been speculated to be attributed to a higher intrinsic activity of fluopyram compared with boscalid, there has been no evidence to suggest differences in intrinsic activity of these two chemistries in a baseline population of $A$. solani (Gudmestad et al. 2013). Therefore, it is more likely that fluopyram binds at a different site on the iron sulfur protein or elsewhere in complex II than boscalid and is unaffected by the same mutations (Avenot and Michailides 2010; Gudmestad et al. 2013). However, the increased and widespread application of fluopyram in commercial potato fields will place significant selection pressure on the early blight pathogen and, in turn, may lead to the development of resistance. Given the ability of A. solani to develop resistance to SDHI, QoI, and anilino-pyrimidine (AP) fungicides, continued monitoring of further resistance development is an important consideration (Fairchild et al. 2013; Fonseka and Gudmestad 2016; Gudmestad et al. 2013; Pasche et al. 2004).

In our previous study, A. solani isolates possessing the D123E mutation made up 1.5\% of isolates collected in 2011 (Mallik et al. 2014). In a more recent survey from 2013 through 2015, D123E-mutant isolates were recovered at significantly higher frequencies of 5 to $12 \%$ of isolates collected (Bauske et al. 2018). However, little is known about the sensitivity of $A$. solani isolates possessing the D123E mutation to SDHI fungicides in vitro or in vivo. As a result, it becomes critical to determine the potential causes associated with the increase in frequency of D123Emutant $A$. solani isolates and evaluate the sensitivity of these isolates under the application of SDHI fungicides. The specific objectives of the current study were to (i) determine in vitro sensitivity of $A$. solani isolates possessing the D123E mutation to the SDHI fungicides boscalid and fluopyram, (ii) determine the disease control of D123E-mutant A. solani isolates under the application of boscalid and fluopyram in vivo, and (iii) determine the influence of fluopyram application method on the frequency of the D123E mutation under field conditions.

\section{Materials and Methods}

A. solani isolate selection. Over 1,300 A. solani isolates were collected from 11 states across the United States and characterized for the presence of mutations conferring QoI and SDHI resistance as part of a previous study in our research program (Bauske et al. 2018). In a previous survey from 2011 to 2012, 67 A. solani isolates were characterized for presence of SDHI resistance mutations and a single isolate in this study was determined to possess the D123E mutation (Mallik et al. 2014). In the more recent study from 2013 to 2015, the D123E mutation was detected in 118 A. solani isolates of the 1,323 isolates collected, representing 12\% of the population sampled in 2015 (Bauske et al. 2018). All isolates collected in the previous study possessing the D123E mutation were selected for these experiments (Table 1).

In vitro sensitivity of D123E-mutant $A$. solani isolates to SDHI fungicides. In vitro sensitivity was evaluated via conidial germination assays conducted as previously described (Gudmestad et al. 2013) using 7- to 14-day-old cultures of $A$. solani maintained under continuous fluorescent light at $22 \pm 2{ }^{\circ} \mathrm{C}$. A glass rod was used to free conidia from the surface of CV8 media using sterile, distilled water under aseptic conditions. The conidial concentration of the suspension was adjusted to $2 \times 10^{4}$ conidia/ml and $150 \mu \mathrm{l}$ was added to the surface of fungicide-amended media. Media containing $2 \%$ laboratory-grade agar (A360-500; Fisher Scientific, Pittsburgh) were amended with technical-grade boscalid (99\% active ingredient [a.i.]; BASF Corporation, Research Triangle Park, NC) or fluopyram (98.78\% a.i.; Bayer CropScience, Monheim am Rhein, Germany) dissolved in acetone (fungicide at approximately $10 \mathrm{mg} / \mathrm{ml}$ ) and diluted in deionized water to reach final concentrations of $0,0.01$, $0.1,1,10$, and $100 \mathrm{mg} / \mathrm{ml}$. The final concentration of acetone in all media was $0.1 \%$ by volume. Salicylhydroxamic acid was dissolved in methanol and added to the media to reach a final concentration of $100 \mathrm{mg} / \mathrm{ml}$ to be consistent with previous SDHI studies (Gudmestad et al. 2013; Pasche et al. 2005).
For all in vitro conidial germination assays, petri plates were incubated at $21^{\circ} \mathrm{C}$ under continuous light for $4 \mathrm{~h}$ prior to evaluation. Following incubation, 50 conidia were examined for the development of one germ tube as long as the conidium, or multiple germ tubes developing from one conidium, using a microscope at $\times 100$ magnification (Gudmestad et al. 2013; Pasche et al. 2005). All experiments were performed twice, with two replicates for each fungicide concentration. In total, $118 \mathrm{~A}$. solani isolates possessing the D123E mutation were evaluated for in vitro sensitivity to boscalid and fluopyram in 20 trials, with 9 to 13 isolates included in each trial. Control isolates 13-1, a wild-type A. solani isolate, and 526-3, a QoI-resistant A. solani isolate, were included in each trial as internal controls. In addition, individual A. solani isolates possessing the H278R, H133R, or H134R mutation with effective concentration at which the fungal growth is inhibited by $50 \%\left(\mathrm{EC}_{50}\right)$ values $<5.0$ for boscalid (Mallik et al. 2014) were also included. These five isolates were reassayed in vitro, in two separate trials as described above, to insure that the original reported $\mathrm{EC}_{50}$ values were precise.

Disease control of D123E-mutant $A$. solani isolates under the application of boscalid and fluopyram in vivo. An in vivo experiment was designed to determine whether isolates possessing the D123E mutation had a selective advantage in the presence of fluopyram despite having no resistance to fluopyram in vitro. In all, 15 A. solani isolates were selected for in vivo evaluation based on in vitro boscalid and fluopyram sensitivity (Table 2), including 5 D123E-mutant isolates, 3 SDHI-sensitive but QoI-resistant isolates, and 2 wild-type isolates. The remaining five $A$. solani isolates possessed SDHI resistance mutations such as H278R, H134R, or H133R. Isolates with these mutations possess a low level of insensitivity to boscalid and but sensitivity to fluopyram. $\mathrm{EC}_{50}$ values of selected isolates ranged from 3.01 to $7.34 \mu \mathrm{g} / \mathrm{ml}$ for boscalid and from 0.11 to $3.13 \mu \mathrm{g} / \mathrm{ml}$ for fluopyram. Additionally, preliminary results

Table 1. Origin and frequency by state of D123E-mutant Alternaria solani isolates collected from 2011 through 2015 evaluated in vitro

\begin{tabular}{lcrc}
\hline States & Year $^{\mathbf{x}}$ & $\boldsymbol{N}^{\mathbf{y}}$ & D123E (\%) \\
\hline Colorado & 2011 & 2 & 0 \\
& 2013 & 80 & $2(2.5)$ \\
& 2014 & 0 & $\ldots$ \\
Michigan & 2015 & 26 & 0 \\
& 2011 & 0 & $\ldots$ \\
& 2013 & 16 & $4(25)$ \\
Minnesota & 2014 & 16 & $1(6.3)$ \\
& 2015 & 0 & $\ldots$ \\
& 2011 & 12 & 0 \\
Nebraska & 2013 & 51 & 0 \\
& 2014 & 38 & 0 \\
& 2015 & 181 & $19(10.5)$ \\
North Dakota & 2011 & 18 & $1(5.5)$ \\
& 2013 & 47 & $6(12.8)$ \\
& 2014 & 58 & $6(10.3)$ \\
Texas & 2015 & 138 & $14(10.1)$ \\
& 2011 & 10 & 0 \\
& 2013 & 83 & $1(1.2)$ \\
Total & 2014 & 80 & $6(7.5)$ \\
& 2015 & 70 & $8(11.4)$ \\
& 2011 & 6 & 0 \\
& 2013 & 86 & $5(5.8)$ \\
& 2014 & 86 & $9(10.5)$ \\
& 2015 & 129 & $23(17.8)$ \\
& 2011 & 67 & $1(1.5)$ \\
& 2013 & 363 & $18(5.0)$ \\
& 2014 & 278 & $22(8.0)$ \\
& 2015 & 544 & $64(11.8)$ \\
\hline
\end{tabular}

$\mathrm{x}$ The 2011 results from Mallik et al. (2014) and the 2013-to-2015 results are from Bauske et al. (2018).

y Total number of isolates collected in each state and in each year.

${ }^{\mathrm{z}}$ Number and frequency of isolates with the D123E mutation collected by state and year. All isolates possessing the D123E that were collected by Bauske et al. (2018) were used in these in vitro studies. 
from a 2013 field study suggested a high prevalence of isolates with the D123E mutation in treatments where fluopyram was applied infurrow but in vitro $\mathrm{EC}_{50}$ values suggested sensitivity to fluopyram. Other A. solani isolates chosen from the 2013 field study to evaluate disease control in vivo included isolates with a range of in vitro fluopyram $\mathrm{EC}_{50}$ values of $3.13 \mu \mathrm{g} / \mathrm{ml}$ or below but also possessed low insensitivity to boscalid. The in vivo sensitivity of $A$. solani isolates to these two SDHI fungicides was evaluated under greenhouse conditions, as previously described (Fonseka and Gudmestad 2016; Gudmestad et al. 2013; Pasche et al. 2004, 2005).

Isolates of the early blight fungus were inoculated onto plants applied with different doses of each SDHI fungicide. Commercial formulations of boscalid (70\% a.i., Endura; BASF Corporation) or fluopyram (41.5\% a.i., Luna; Bayer CropScience) were used. To obtain dose-response curves, 10 -fold fungicide concentrations of the active ingredient were applied to plants $(0,0.1,1,10$, and $100 \mu \mathrm{g} / \mathrm{ml})$. The in vivo sensitivity assay was conducted as a 24 -h preventative test in the greenhouse using tomato plants (cultivar Orange Pixie VFT hybrid; Tomato Growers Supply Company, Fort Myers, FL) chosen for their susceptibility to early blight, compact size, and the fact that earlyblight-affected leaves do not dehisce under severe disease conditions. Three tomato seeds were sown in each $10-\mathrm{cm}^{3}$ plastic pot containing
Sunshine Mix LC1 (Sun Gro Horticulture Inc., Bellevue, WA) and, following emergence, plants were thinned to obtain two uniformly sized plants per pot. Plants were treated when the first three leaves were fully expanded and plants had reached a height of 15 to $20 \mathrm{~cm}$. Fungicide was applied preventatively using a Generation III Research Sprayer (Devries Manufacturing, Hollandale, MN), starting with the lowest concentration, and rinsed thoroughly with distilled water between fungicide chemistries. Fungicide concentrations were applied from lowest to highest $(0,0.1,1,10$, and $100 \mu \mathrm{g} / \mathrm{ml})$ to avoid the need for rinsing between each concentration.

For inoculation of $A$. solani, isolates maintained on solid CV8 media for 7 to 14 days under continuous fluorescent light at $22 \pm 2^{\circ} \mathrm{C}$ were used to prepare a suspension of $2 \times 10^{5}$ conidia/ml of sterile distilled water. Tomato plants were inoculated with $50 \mathrm{ml}$ of conidial suspension/ plant $24 \mathrm{~h}$ postfungicide application using a Preval paint-spray gun (Preval Sprayer Division; Precision Valve Corporation, Yonkers, NY). Inoculated plants were kept in individual humidity chambers (Phytotronic Inc., Earth City, MO) for $24 \mathrm{~h}$ at $>95 \%$ relative humidity and $22 \pm 2{ }^{\circ} \mathrm{C}$ and subsequently transferred to confinement chambers (plastic chambers with open ceilings) on greenhouse benches to minimize interisolate interference and maintained at $25 \pm 2^{\circ} \mathrm{C}$, with daily application of water. Percent disease severity was visually evaluated on

Table 2. Origin, mutation characterization, and in vitro boscalid and fluopyram sensitivity of Alternaria solani isolates chosen for in vivo experiment

\begin{tabular}{|c|c|c|c|c|c|c|}
\hline SDHI mutation ${ }^{x}$ & Isolate & State of origin & Collection year & F129L $L^{y}$ & Boscalid EC $\mathrm{E}_{50}(\mu \mathrm{g} / \mathrm{ml})^{\mathrm{z}}$ & Fluopyram $\mathrm{EC}_{50}(\mu \mathrm{g} / \mathrm{ml})^{2}$ \\
\hline SDHI-sensitive & $1342-8$ & Nebraska & 2013 & $\mathrm{M}$ & 4.01 & 1.78 \\
\hline SDHI-sensitive & $1331-6$ & Texas & 2013 & M & 3.12 & 1.20 \\
\hline SDHI-sensitive & $1393-5$ & North Dakota & 2013 & M & 4.12 & 2.08 \\
\hline SDHI-sensitive & $1393-8$ & North Dakota & 2013 & WT & 3.21 & 0.39 \\
\hline SDHI-sensitive & $1486-11$ & North Dakota & 2014 & WT & 3.01 & 0.45 \\
\hline $\mathrm{H} 133 \mathrm{R}$ & $1172-8$ & Idaho & 2011 & M & 6.28 & 2.15 \\
\hline H133R & $1176-3$ & Idaho & 2011 & M & 6.80 & 2.33 \\
\hline H134R & $1174-9$ & Idaho & 2011 & M & 5.89 & 2.09 \\
\hline H134R & $1231-9$ & North Dakota & 2012 & M & 3.34 & 1.55 \\
\hline $\mathrm{H} 278 \mathrm{R}$ & $1172-6$ & Idaho & 2011 & M & 5.01 & 0.11 \\
\hline D123E & $1342-6$ & Nebraska & 2013 & M & 4.81 & 0.26 \\
\hline D123E & $1332-2$ & Texas & 2013 & M & 7.34 & 1.74 \\
\hline D123E & $1364-1$ & Colorado & 2013 & M & 4.54 & 0.38 \\
\hline D123E & $1393-1$ & North Dakota & 2013 & WT & 4.21 & 2.46 \\
\hline D123E & $1393-18$ & North Dakota & 2013 & WT & 6.18 & 3.13 \\
\hline
\end{tabular}

${ }^{\mathrm{x}}$ Isolate possesses none of the five mutations on three $A s S d h$ genes conferring succinate dehydrogenase-inhibiting (SDHI) resistance.

${ }^{\mathrm{y}} \mathrm{M}=$ mutant isolate with the F129L mutation conferring quinone outside inhibitor resistance and WT = wild-type isolate.

${ }^{\mathrm{z}} \mathrm{EC}_{50}=$ the effective concentration at which fungal growth is inhibited by $50 \%$.

Table 3. Fungicide treatment, use rates, and application schedule of treatments evaluated in field trials conducted in 2013 and 2015 in northeastern North Dakota

\begin{tabular}{|c|c|c|c|}
\hline Treatment & Rate of active ingredient & Schedule $^{\mathrm{z}}$ & Interval \\
\hline 1 Nontreated & $\ldots$ & $\ldots$ & $\ldots$ \\
\hline 2 Chlorothalonil & $1.25 \mathrm{~kg} / \mathrm{ha}$ & Full season & 7-day \\
\hline 3 Mancozeb & $1.80 \mathrm{~kg} / \mathrm{ha}$ & Full season & 7-day \\
\hline 4 Fenamidone & $0.25 \mathrm{~kg} / \mathrm{ha}$ & 1,3 & 7-day \\
\hline + Sticker or extender adjuvant & $0.1 \%(\mathrm{vol} / \mathrm{vol})$ & $\ldots$ & $\ldots$ \\
\hline + Mancozeb & $1.80 \mathrm{~kg} / \mathrm{ha}$ & $\ldots$ & $\ldots$ \\
\hline + Chlorothalonil & $0.75 \mathrm{~kg} / \mathrm{ha}$ & 2 & $\ldots$ \\
\hline + Chlorothalonil & $1.25 \mathrm{~kg} / \mathrm{ha}$ & $4,6,8-10$ & $\ldots$ \\
\hline Fluopyram or pyrimethanil & 0.09 or $0.27 \mathrm{~kg} / \mathrm{ha}$ & 5 & $\ldots$ \\
\hline+ Mancozeb & $1.80 \mathrm{~kg} / \mathrm{ha}$ & $\cdots$ & $\cdots$ \\
\hline+ Pyrimethanil & $0.30 \mathrm{~kg} / \mathrm{ha}$ & 7 & $\ldots$ \\
\hline + Mancozeb & $1.80 \mathrm{~kg} / \mathrm{ha}$ & $\ldots$ & $\ldots$ \\
\hline 5 Fluopyram & $0.35 \mathrm{~kg} / \mathrm{ha}$ & In-furrow & At planting \\
\hline 6 Fluopyram & $0.35 \mathrm{~kg} / \mathrm{ha}$ & In-furrow & At planting \\
\hline + Bacillus subtilis & 4.68 liters/ha & $\ldots$ & $\ldots$ \\
\hline 7 Fluopyram & $0.35 \mathrm{~kg} / \mathrm{ha}$ & In-furrow & At planting \\
\hline + B. subtilis & 9.36 liters/ha & $\ldots$ & $\ldots$ \\
\hline 8 Imidacloprid & $0.15 \mathrm{~kg} / \mathrm{ha}$ & In-furrow & At planting \\
\hline + Fluopyram & $0.15 \mathrm{~kg} / \mathrm{ha}$ & $\ldots$ & $\ldots$ \\
\hline+ B. subtilis & 4.68 liter/ha & $\ldots$ & $\ldots$ \\
\hline
\end{tabular}

${ }^{\mathrm{z}}$ Number of weeks that fungicide was applied. 
three fully expanded true leaves on each of two plants/pot, one pot/ replicate, and three replicates at 6,9 , and 12 days postinoculation. The in vivo experiment was performed twice.

Influence of fluopyram application method on the frequency of the D123E mutation. Field trails were conducted in 2013 and 2015 to evaluate the efficacy of fluopyram applied in-furrow at planting and as a foliar application during the growing season. Trials were performed under irrigated conditions as randomized complete block designs with four replications near Inkster, ND. Treatments were planted to cultivar Ranger Russet, chosen for its susceptibility to early blight, in four-row plots approximately $3.6 \mathrm{~m}$ wide and $9.0 \mathrm{~m}$ in length. The experiment consisted of eight separate treatments, including a nontreated control (Table 3). Two separate treatments consisted of foliar application of the standard protectants chlorothalonil and mancozeb, respectively, applied at the highest labeled rate at a 7-day interval throughout the growing season. A treatment consisting of multiple foliar applications of a QoI, SDHI, demethylation inhibitor (DMI), or AP fungicide, tank mixed or applied in alternation with standard protectants, was also included (Table 3). Three treatments included an in-furrow application of fluopyram alone together with two different rates of the biological control Bacillus subtilis (Serenade Soil; Bayer CropScience). An additional treatment consisting of the infurrow application of the systemic insecticide imidacloprid (Admire Pro; Bayer CropScience) applied along with fluopyram and B. subtilis was included in the trial in both years (Table 3 ).

In-furrow applications were applied using a planter-mounted $\mathrm{CO}_{2}$ sprayer with a single nozzle with 6501 tip directed at the seed-piece. All foliar fungicides were applied with water volumes of 560 liters ha $^{-1}$ at $375 \mathrm{kPa}$ to ensure adequate coverage. Percent early blight severity was recorded in the center two rows at approximately 7-day intervals beginning in early to mid-July (about 60 to 70 days after planting), depending on disease pressure. Early blight disease severity evaluations, taken on a scale of 0 to $100 \%$ diseased leaf tissue, continued for 11 weeks, not surpassing 7 days after the final foliar fungicide application (Pasche and Gudmestad 2008).

For inoculation of the treatments, four $A$. solani isolates, two containing the F129L mutation and two wild type, were grown under constant fluorescent light for 2 weeks on CV8 medium at room temperature $\left(22 \pm 2^{\circ} \mathrm{C}\right)$. Distilled water was added to the cultures and conidia were dislodged with a glass rod and diluted in $0.25 \%$ gelatin to a concentration of $6.7 \times 10^{3}$ conidia/ml. This suspension was applied to the outside two rows of each four-row treatment at a rate of $104 \mathrm{ml} /$ row on two separate days, approximately mid-July and early August, using custom ATV application equipment.

Detection of mutations associated with SDHI resistance in A. solani isolates collected from field treatments. Following the last foliar disease severity rating, approximately 10 infected leaves were sampled at random from all four replicates of each treatment, including the nontreated control, placed in unsealed plastic bags inside a cooler, and transported back to the laboratory. Early blight lesions on infected leaf tissue were then transferred to $1.5 \%$ agar media and isolations were made as previously described (Holm et al. 2003). DNA extractions and polymerase chain reaction (PCR) was performed on each of the isolates collected as previously described (Bauske et al. 2018). Approximately 40 A. solani isolates from each treatment were collected each year and assayed to determine the prevalence of isolates possessing the D123E mutation among treatments. DNA extractions from all isolates collected in both years using a modified cetyltrimethylammonium bromide method (Bauske et al. 2018; Mallik et al. 2014; Stewart and Via 1999). Mutations associated with
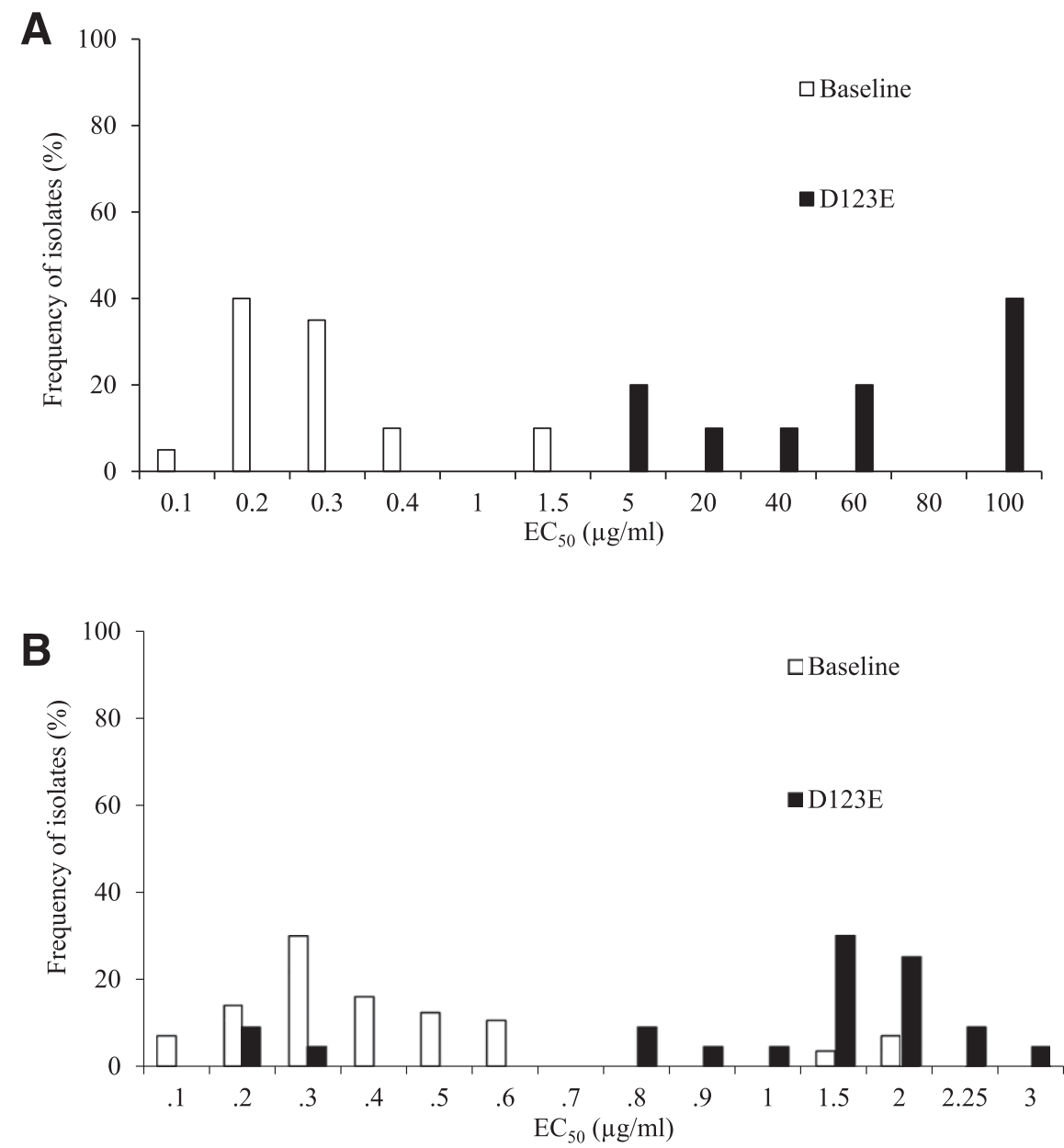

Fig. 1. Frequency distribution of sensitivity of 57 baseline Alternaria solani isolates and $118 \mathrm{D} 123 \mathrm{E}$-mutant $A$. solani isolates to $\mathbf{A}$, boscalid and $\mathbf{B}$, fluopyram, based on in vitro methods to determine effective concentration that inhibits spore germination by $50 \%$ compared with nontreated control $\left(\mathrm{EC}_{50} \mu \mathrm{g} / \mathrm{ml}\right)$. Sensitivities for baseline $A$. solani isolates were conducted according to Gudmestad et al. (2013). 
SDHI resistance were detected in A. solani isolates using previously described PCR methods (Bauske et al. 2018; Mallik et al. 2014). An SDH multiplex PCR specific for point mutations in the AsSdhB, AsSdhC, or $A s S d h D$ genes, as well as mismatch amplification analysis (MAMA)PCR to detect mutations in the $A s S d h B$ gene, were performed to detect the presence of one of five previously mentioned mutations associated with SDHI resistance in A. solani (Bauske et al. 2018; Mallik et al. 2014). Following MAMA-PCR, the H278Y and the H278R mutations in the $A s S d h B$ gene yielded a 127-bp amplification product on agarose gel in separate reactions. A. solani isolates possessing the H134R mutation in the $A s S d h C$ gene yielded a 235-bp product along with a 457-bp product, whereas isolates possessing the H133R mutation in the AsSdhD gene yielded a 235-bp product accompanied by a 72-bp product on agarose gel following SDH multiplex PCR. The D123E mutation in the $A s S d h D$ gene was detected in $A$. solani isolates using an additional PCR assay, which yielded a 127-bp product on agarose gel if the mutation was present (Bauske et al. 2018).

Statistical analysis. To calculate $\mathrm{EC}_{50}$ values for in vitro experiments, the percent reduction in germination relative to the nonfungicideamended control was calculated and regressed against the $\log _{10}$ fungicide concentration. The concentration determined to reduce germination by half, compared with a concentration of $0 \mu \mathrm{g} / \mathrm{ml}$, was extrapolated from the $50 \%$ intercept $\left(\mathrm{EC}_{50}\right.$ value) using the Statistical Analysis System (SAS Institute Inc., Cary, NC). Approximate limits for a $95 \%$ confidence interval for the two internal controls were calculated as a measure of assay reproducibility (Wong and Wilcox 2002). Trials in which the $\mathrm{EC}_{50}$ values of the internal controls were within the $95 \%$ confidence internal were included in the analysis. Experiments were analyzed separately and an $F$ test was used to assess homogeneity of variance among experiments. To determine significant differences in in vitro sensitivity to boscalid and fluopyram between baseline $A$. solani isolates and isolates possessing the D123E mutation, analysis of variance (ANOVA) was performed on the combined results using PROC GLM in SAS. Mean $\mathrm{EC}_{50}$ values for boscalid and fluopyram of baseline and D123E-possessing isolates were compared using Fisher's protected least significant difference (LSD) test $(P=0.05)$.

In vivo experiments were arranged as split-plot randomized complete block designs, with $A$. solani isolates as the main plot and fungicide concentrations as the split plots. For each isolate at all fungicide concentrations, disease severity data were transformed to percent disease control using the formula 1 - (percent diseased tissue/ percent diseased tissue in nontreated plants) $\times 100$ (Fonseka and Gudmestad 2016; Gudmestad et al. 2013). Levene's test was conducted to determine homogeneity of variance between two independent experiments (Milliken and Johnson 1992). ANOVA was performed separately for isolate-fungicide group combination at each of the four fungicide concentrations $(0.1,1,10$, and $100 \mu \mathrm{g} / \mathrm{ml})$ using SAS, and $t$ tests were used on the combined data to determine differences at each fungicide concentration. Area under the dose response curve (AUDRC), or area under the disease progress curve across all doses of fungicide, was calculated to determine significant differences in disease control provided by boscalid and fluopyram in controlling SDHI-sensitive and SDHI-resistant A. solani isolates (Shaner and Finney 1977). AUDRC is the area under the disease progress curve for dose-response curves calculated as discussed below by substituting fungicide rate for observation.

For field trials, percent early blight severity, recorded as previously described above, was used to calculate the area under the disease progress curve (AUDPC) as follows (Shaner and Finney 1977):

$$
\text { AUDPC }=\sum_{i=1}^{n}\left[\left(\mathrm{~W}_{i+1}+\mathrm{W}_{i}\right) / 2\right]\left[\mathrm{t}_{i+1}-t_{i}\right]
$$

Where $W_{i}=$ the percent foliar disease severity at the $i$ th observation, $t_{i}=$ the time in days at the $i$ th observation, and $n=$ the total number of observations. The relative area under the disease progress curve (RAUDPC) was calculated for each treatment of the replicated trials from each year by dividing AUDPC values by the total area of the graph and analyzed using ANOVA (Proc GLM, version 9.3; SAS Institute Inc.). Fisher's protected LSD test $(P=0.05)$ was used to differentiate mean RAUDPC values (Pasche and Gudmestad 2008). One-way ANOVA was conducted to analyze the frequency of each mutation among isolates collected from field treatments in 2013 and 2015. Levene's test was used to determine whether 2013 and 2015 mutation frequency results could be combined for analysis. Due to nonhomogeneity of variance $(P<0.05)$ for all mutations (H278Y, H278R, H134R, H133R, D123E, and the wild type) between years, separate ANOVA were conducted on the percentage frequency data for each mutation among treatments. Fisher's protected LSD test $(P=0.05)$ was also conducted to determine significant differences among mean mutation frequencies across treatments.

\section{Results}

Determination of in vitro sensitivity of $A$. solani isolates possessing the D123E mutation to the SDHI fungicides boscalid and fluopyram. Sensitivity to boscalid in A. solani isolates with the D123E mutation ranged from 4.5 to $>100 \mu \mathrm{g} / \mathrm{ml}$ (Fig. 1A), with a mean of $60.7 \mu \mathrm{g} / \mathrm{ml}$, and were significantly higher compared

Table 4. Mean in vivo percent disease control of Alternaria solani isolates by boscalid as determined in greenhouse assays ${ }^{\mathrm{v}}$

\begin{tabular}{|c|c|c|c|c|c|c|c|}
\hline \multirow[b]{2}{*}{ Isolate } & \multirow[b]{2}{*}{ Mutation $^{w}$} & \multirow[b]{2}{*}{$\mathrm{EC}_{50}(\mu \mathrm{g} / \mathrm{ml})^{\mathrm{x}}$} & \multicolumn{4}{|c|}{ Boscalid concentration $(\mu \mathrm{g} / \mathrm{ml})$} & \multirow[b]{2}{*}{ AUDRC $^{\mathbf{y}}$} \\
\hline & & & 0.1 & 1 & 10 & 100 & \\
\hline $1342-8$ & SDHI-sensitive & 4.01 & $40.0 \mathrm{a}$ & $76.1 \mathrm{~b}$ & $97.6 \mathrm{a}$ & $100.0 \mathrm{a}$ & $9,727.7 \mathrm{a}$ \\
\hline $1331-6$ & SDHI-sensitive & 3.12 & $40.0 \mathrm{a}$ & $77.1 \mathrm{ab}$ & $98.0 \mathrm{a}$ & $100.0 \mathrm{a}$ & $9,749.7 \mathrm{a}$ \\
\hline $1393-5$ & SDHI-sensitive & 4.12 & 39.9 a & $77.4 \mathrm{a}$ & $98.1 \mathrm{a}$ & $100.0 \mathrm{a}$ & $9,757.5 \mathrm{a}$ \\
\hline $1393-8$ & SDHI-sensitive & 3.21 & $39.1 \mathrm{~b}$ & $77.7 \mathrm{a}$ & $97.3 \mathrm{a}$ & $100.0 \mathrm{a}$ & $9,718.0 \mathrm{a}$ \\
\hline $1486-11$ & SDHI-sensitive & 3.01 & $39.2 \mathrm{~b}$ & $78.0 \mathrm{a}$ & $97.9 \mathrm{a}$ & $100.0 \mathrm{a}$ & $9,750.0 \mathrm{a}$ \\
\hline $1172-8$ & $\mathrm{H} 133 \mathrm{R}$ & 6.28 & $18.8 \mathrm{f}$ & $44.4 \mathrm{f}$ & $76.6 \mathrm{fg}$ & $95.4 \mathrm{e}$ & $8,313.6 \mathrm{f}$ \\
\hline $1176-3$ & H133R & 6.80 & $18.9 \mathrm{f}$ & $45.1 \mathrm{f}$ & $77.4 \mathrm{ef}$ & $97.7 \mathrm{~d}$ & $8,456.3 \mathrm{e}$ \\
\hline $1174-9$ & H134R & 5.89 & $19.8 \mathrm{de}$ & $53.0 \mathrm{c}$ & $83.3 \mathrm{~b}$ & $100.0 \mathrm{a}$ & $8,894.7 \mathrm{~b}$ \\
\hline $1231-9$ & H134R & 3.34 & $20.4 \mathrm{~d}$ & $53.5 \mathrm{c}$ & $82.9 \mathrm{~b}$ & $100.0 \mathrm{a}$ & $8,877.4 \mathrm{~b}$ \\
\hline $1172-6$ & $\mathrm{H} 278 \mathrm{R}$ & 5.01 & $22.9 \mathrm{c}$ & $53.1 \mathrm{c}$ & $81.1 \mathrm{c}$ & $98.5 \mathrm{c}$ & $8,717.1 \mathrm{c}$ \\
\hline $1342-6$ & D123E & 4.81 & $18.8 \mathrm{f}$ & $44.8 \mathrm{f}$ & $77.9 \mathrm{e}$ & $97.5 \mathrm{~d}$ & $8,470.5 \mathrm{e}$ \\
\hline $1332-2$ & D123E & 7.34 & $19.6 \mathrm{e}$ & $51.3 \mathrm{~d}$ & $83.2 \mathrm{~b}$ & $99.1 \mathrm{~b}$ & $8,840.2 \mathrm{~b}$ \\
\hline $1364-1$ & D123E & 4.54 & $18.8 \mathrm{f}$ & $46.7 \mathrm{e}$ & $77.8 \mathrm{e}$ & $97.4 \mathrm{~d}$ & $8,470.7 \mathrm{e}$ \\
\hline 1393-1 & D123E & 4.21 & $22.5 \mathrm{c}$ & $53.4 \mathrm{c}$ & $79.6 \mathrm{~d}$ & $97.3 \mathrm{~d}$ & $8,590.6 \mathrm{~d}$ \\
\hline $1393-18$ & D123E & 6.18 & $18.6 \mathrm{f}$ & $44.2 \mathrm{f}$ & $76.3 \mathrm{~g}$ & $95.4 \mathrm{e}$ & $8,298.7 \mathrm{f}$ \\
\hline $\mathrm{LSD}^{\mathrm{z}}$ & $\ldots$ & $\ldots$ & 0.7 & 1.1 & 1.0 & 0.5 & 56.8 \\
\hline
\end{tabular}

v Numbers followed by different lowercase letters are significantly different according to Fisher's protected least significant difference test at the $P=0.05$ level.

${ }^{w}$ Mutation presence conferring succinate dehydrogenase-inhibiting (SDHI) (D123E, H133R, H134R, and H278R) and quinone outside inhibitor (F129L) resistance.

${ }^{\mathrm{x}}$ Effective concentration at which the fungal growth is inhibited by $50 \%\left(\mathrm{EC}_{50}\right)$ values for boscalid from in vitro assays.

y Area under dose response curve.

${ }^{\mathrm{z}}$ Least significant difference at the $P=0.05$ level. 
with baseline isolates according to Fisher's protected LSD test $(F=$ 108.21, $P<0.0001$ ), which ranged from 0.1 to $1.5 \mu \mathrm{g} / \mathrm{ml}$ (Fig. 1A), with a mean of $0.33 \mu \mathrm{g} / \mathrm{ml}$. Sensitivity to fluopyram in A. solani isolates with the D123E mutation ranged from 0.2 to $3 \mu \mathrm{g} / \mathrm{ml}$, with a mean $\mathrm{EC}_{50}$ value of $1.5 \mu \mathrm{g} / \mathrm{ml}$, and were also significantly higher $(F=113.64$, $P<0.0001)$ compared with baseline isolates, which ranged from 0.1 to $0.6 \mu \mathrm{g} / \mathrm{ml}$ (Fig. 1B), with a mean $\mathrm{EC}_{50}$ value of $0.31 \mu \mathrm{g} / \mathrm{ml}$.

Disease control of D123E-mutant $A$. solani isolates under the application of boscalid and fluopyram in vivo. Independent analysis of in vivo disease control experiments for boscalid and fluopyram determined that variances were homogenous $(P=0.05)$, and experiments were combined for further analysis. In the analysis of experimental data evaluating each fungicide, a significant interaction was observed between isolate and fungicide concentration $(P<$ $0.0001)$ for percent disease control. Significant effects $(P<0.0001)$ were also observed for isolate and fungicide concentration for experiments evaluating percent disease control provided by boscalid and fluopyram.

Control of early blight on tomato treated with boscalid at all fungicide concentrations was significantly lower when caused by $A$. solani isolates with the D123E mutation compared with SDHI-sensitive isolates (Table 4). AUDRC values for all five D123E-mutant isolates, ranging from 8,840.2 to 8,298.7, were also significantly lower compared with SDHI-sensitive isolates, ranging from 9,757.5 to 9,718.0 and indicating reduced disease control in vivo for $A$. solani isolates possessing the D123E mutation. Five $A$. solani isolates possessing the H278R, H134R, or H133R mutations but a moderate level of resistance to boscalid in vitro were also found to have significantly reduced disease control at all boscalid concentrations compared with SDHI-sensitive isolates (Table 4). Dose response curves for boscalid indicate that $A$. solani isolates possessing the D123E, H278R, H134R, or H133R mutations were controlled similarly at all fungicide concentrations (Table 4; Fig. 2A).

Significant differences in early blight disease control in vivo with fluopyram were also observed among $A$. solani isolates. Percent disease control at each concentration of fluopyram was significantly lower for D123E-mutant isolates compared with SDHI-sensitive isolates, as well as isolates possessing mutations conferring SDHI resistance such as H278R, H134R, and H133R (Table 5). All five D123E-mutant isolates evaluated were determined to have significantly reduced disease control compared with all other $A$. solani isolates evaluated across concentrations of $0.1,1$, and $10 \mu \mathrm{g} / \mathrm{ml}$. AUDRC values for D123E-mutant isolates, ranging from 7,938.8 to 7,064.3, were significantly lower compared with SDHI-sensitive isolates at 9,887.4 to 9,760.5 and isolates possessing the H278R, H134R, or H133R mutations at 9,761.4 to $8,627.2$, indicating significantly reduced disease control of D123Emutant isolates by fluopyram in vivo (Table 5). Based on these data, disease control provided by fluopyram of every A. solani isolate with the D123E mutation was significantly lower than disease control of SDHI-sensitive isolates and isolates possessing the H134R, H278R, and H133R mutations (Table 5; Fig. 2B). Even at the highest concentration of fluopyram $(100 \mu \mathrm{g} / \mathrm{ml})$, disease control of three of five D123E-mutant $A$. solani isolates (1332-2, 1364-1, and 139318) evaluated in vivo was significantly lower than the disease control
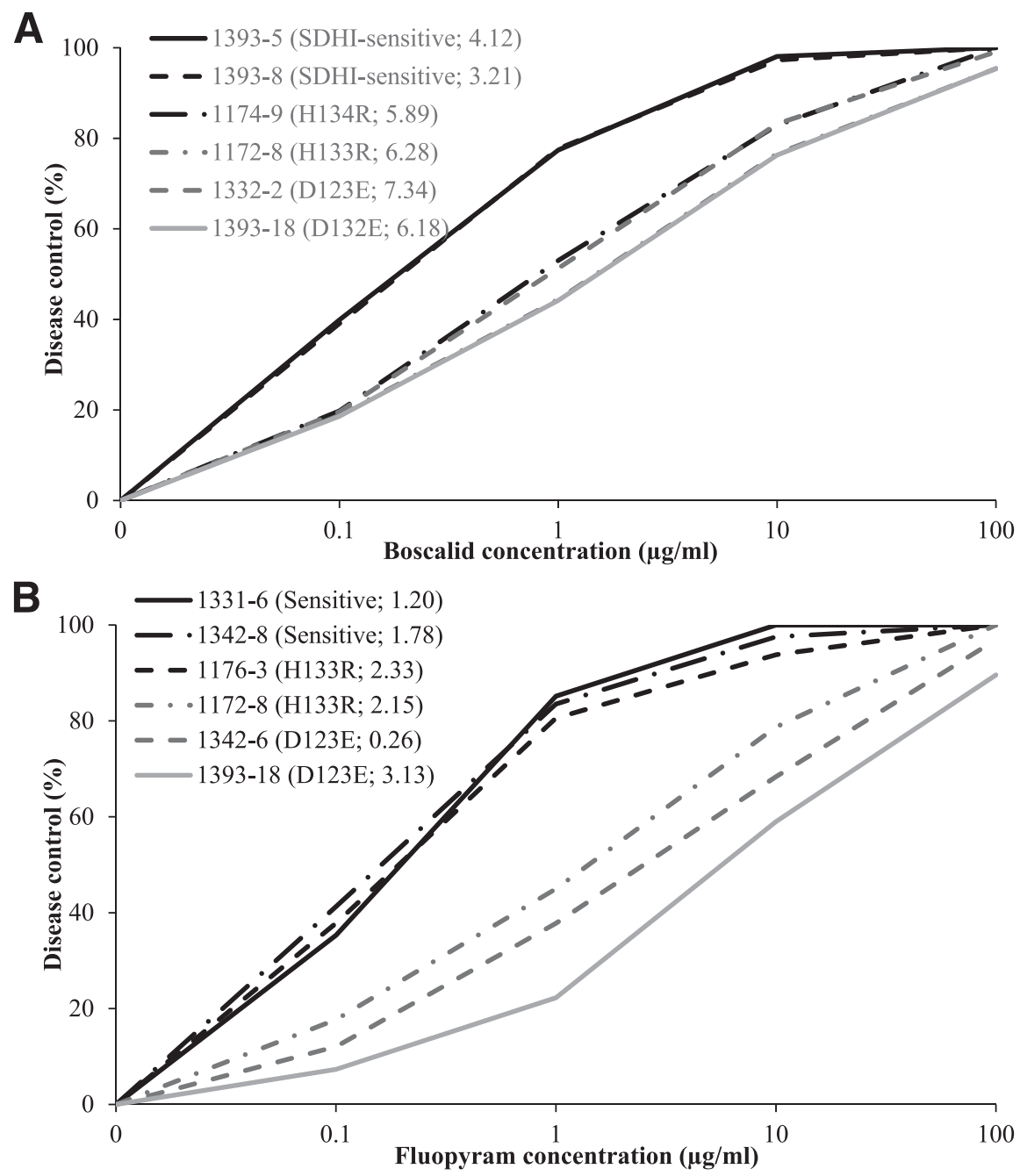

Fig. 2. Mean in vivo percent disease control of Alternaria solani isolates by A, boscalid and $\mathbf{B}$, fluopyram as determined in greenhouse assays. The 6 of 15 isolates in the dose response curve represent the highest and lowest sensitivities to each fungicide of succinate dehydrogenase-inhibiting (SDHI)-sensitive isolates, SDHI-mutant isolates possessing the H133R or H134R mutations, and D123E-mutant isolates. 
of SDHI-sensitive isolates and isolates possessing the H134R, H278R, or H133R mutations (Table 5).

Determination of the influence of fluopyram application method on the frequency of mutations conferring SDHI resistance. Results from field trials conducted in northeast North Dakota demonstrated that there were no differences among fungicide treatments in the control of early blight in 2013 but significant differences were observed among treatments in 2015 (Fig. 3). In 2015, only treatment 4, which consisted of multiple foliar applications of a QoI, SDHI, DMI, or AP fungicide tank mixed or applied in alternation with mancozeb or chlorothalonil, was determined to have significantly lower early blight severity compared with all other treatments. However, in both years of the trial, all fungicide treatments provided significant control of early blight compared with the nontreated control plots.

In both 2013 and 2015, when A. solani isolates were collected from multiple treatments in field trials, significant differences were observed in the frequency of various mutations detected among treatments (Table 6). In nontreated plots receiving no fungicide applications, wild-type A. solani isolates determined to possess none of the five mutations associated with SDHI resistance were detected at significantly higher frequencies compared with all other treatments in both years (Table 6). It was also determined that the frequency of A. solani isolates possessing the D123E mutation was significantly higher in treatments where fluopyram had been applied in-furrow (Table 6). In both years, none of the isolates collected from nontreated plots or plots receiving foliar applications of chlorothalonil and mancozeb possessed the D123E mutation (Table 6). A. solani isolates with the D123E mutation were detected at significantly higher frequencies when fluopyram was applied alone and infurrow at planting compared with all other treatments in both years, comprising 35.0 and $37.5 \%$ of isolates collected from these treatments in 2013 and 2015, respectively. The frequency of $A$. solani isolates with the D123E mutation in treatments receiving $B$. subtilis (Serenade Soil) in-furrow in combination with fluopyram was also significantly higher than all other treatments, except fluopyram applied alone in-furrow (Table 6). Interestingly, when B. subtilis was applied in combination with fluopyram in-furrow at planting, the frequency of the D123E mutation in A. solani isolates recovered was significantly lower compared with fluopyram applied in-furrow alone (Table 6). The rate of $B$. subtilis applied with fluopyram also appeared to have a significant effect on the frequency of the
D123E mutation detected at the end of the season. When a low rate of $B$. subtilis (4.7 liters/ha) was applied in combination with fluopyram in-furrow, the frequency of $A$. solani isolates with the D123E mutation was 20 and 15\% in 2013 and 2015, respectively, which was determined to be significantly higher than the 0 and $5 \%$ of isolates detected when a higher rate of $B$. subtilis (9.4 liters/ha) was used in combination with fluopyram in-furrow at planting. There were additional differences in the frequencies of the H278Y, H278R, H134R, and H133R mutations observed among treatments in both years but no significant increase in the presence of these mutations was observed in plots receiving the in-furrow application of fluopyram compared with plots receiving other foliar fungicide treatments or the nontreated control (Table 6).

\section{Discussion}

This study is the first to characterize reduced sensitivity to fluopyram in A. solani using both in vivo and field experiments. The D123E mutation was previously characterized as one of five known point mutations on three AsSdh genes in A. solani known to independently confer resistance to the SDHI fungicides boscalid and penthiopyrad (Mallik et al. 2014). In the previous study, only a single isolate out of 67 characterized was identified as possessing the D123E mutation. The initial D123E-mutant A. solani isolate was collected from Nebraska in 2011 and determined to have very high resistance to boscalid and penthiopyrad but was determined to be sensitive to fluopyram (Mallik et al. 2014). This was supported by a number of studies that have identified a lack of cross-resistance between SDHI fungicides boscalid and fluopyram in A. solani, and determined that isolates with high levels of boscalid resistance were sensitive to fluopyram (Fairchild et al. 2013; Gudmestad et al. 2013; Mallik et al. 2014; Miles et al. 2014). In a subsequent survey conducted by our laboratory through the years 2013 through 2015 , A. solani isolates possessing the D123E mutation were identified at much higher frequencies and from multiple states, including Colorado, Michigan, Minnesota, Nebraska, North Dakota, and Texas (Bauske et al. 2018). D123E-mutant isolates increased in frequency in several of these states every year of the survey and comprised $12 \%$ of total isolates collected in 2015 (Bauske et al. 2018). This study was conducted to assist our understanding of the observed increase in the frequency of D123E mutations in A. solani isolates.

Despite the fact that $A$. solani isolates possessing the D123E mutation were not included in the inoculum mixture used to inoculate

Table 5. Mean in vivo percent disease control of Alternaria solani isolates by fluopyram as determined in greenhouse assays ${ }^{\mathrm{v}}$

\begin{tabular}{|c|c|c|c|c|c|c|c|}
\hline \multirow[b]{2}{*}{ Isolate } & \multirow[b]{2}{*}{ Mutations $^{\mathrm{w}}$} & \multirow[b]{2}{*}{$\mathrm{EC}_{50}(\mu \mathrm{g} / \mathrm{ml})^{\mathrm{x}}$} & \multicolumn{4}{|c|}{ Fluopyram concentration $(\mu \mathrm{g} / \mathrm{ml})$} & \multirow[b]{2}{*}{ AUDRC $^{y}$} \\
\hline & & & 0.1 & 1 & 10 & 100 & \\
\hline $1342-8$ & SDHI-sensitive & 1.78 & $41.3 \mathrm{a}$ & $83.5 \mathrm{ab}$ & $97.6 \mathrm{ab}$ & $100.0 \mathrm{a}$ & $9,760.5 \mathrm{~b}$ \\
\hline \multirow[t]{2}{*}{$1331-6$} & SDHI-sensitive & 1.20 & $35.3 \mathrm{c}$ & $85.2 \mathrm{ab}$ & $100.0 \mathrm{a}$ & $100.0 \mathrm{a}$ & $9,887.4 \mathrm{a}$ \\
\hline & SDHI-sensitive & 2.08 & $36.9 \mathrm{bc}$ & $83.9 \mathrm{ab}$ & $100.0 \mathrm{a}$ & $100.0 \mathrm{a}$ & $9,881.8 \mathrm{a}$ \\
\hline $1393-8$ & SDHI-sensitive & 0.39 & $37.8 \mathrm{bc}$ & $82.5 \mathrm{ab}$ & $100.0 \mathrm{a}$ & $100.0 \mathrm{a}$ & $9,875.4 \mathrm{a}$ \\
\hline 1486-11 & SDHI-sensitive & 0.45 & $39.7 \mathrm{ab}$ & $83.3 \mathrm{ab}$ & $99.0 \mathrm{ab}$ & $100.0 \mathrm{a}$ & $9,830.7 \mathrm{ab}$ \\
\hline $1172-8$ & H133R & 2.15 & $17.7 \mathrm{~d}$ & $45.0 \mathrm{c}$ & $78.7 \mathrm{e}$ & $100.0 \mathrm{a}$ & $8,627.2 \mathrm{e}$ \\
\hline $1176-3$ & H133R & 2.33 & $37.8 \mathrm{bc}$ & $80.6 \mathrm{~b}$ & $93.8 \mathrm{c}$ & $100.0 \mathrm{a}$ & $9,559.6 \mathrm{c}$ \\
\hline $1174-9$ & H134R & 2.09 & $17.6 \mathrm{~d}$ & $46.1 \mathrm{c}$ & $82.0 \mathrm{~d}$ & $97.9 \mathrm{ab}$ & $8,700.3 \mathrm{e}$ \\
\hline $1231-9$ & H134R & 1.55 & $19.0 \mathrm{~d}$ & $49.2 \mathrm{c}$ & $83.4 \mathrm{~d}$ & $100.0 \mathrm{a}$ & $8,881.1 \mathrm{~d}$ \\
\hline $1172-6$ & $\mathrm{H} 278 \mathrm{R}$ & 0.11 & $35.0 \mathrm{c}$ & $86.3 \mathrm{a}$ & $97.4 \mathrm{~b}$ & $100.0 \mathrm{a}$ & $9,761.4 \mathrm{~b}$ \\
\hline $1342-6$ & D123E & 0.26 & $12.1 \mathrm{e}$ & $37.8 \mathrm{~d}$ & $68.4 \mathrm{f}$ & $96.9 \mathrm{ab}$ & $7,938.8 \mathrm{f}$ \\
\hline $1332-2$ & D123E & 1.74 & $11.4 \mathrm{e}$ & $35.6 \mathrm{~d}$ & $67.5 \mathrm{f}$ & $96.5 \mathrm{~b}$ & $7,866.1 \mathrm{f}$ \\
\hline $1364-1$ & D123E & 0.37 & $11.3 \mathrm{e}$ & $36.8 \mathrm{~d}$ & $67.5 \mathrm{f}$ & $95.8 \mathrm{~b}$ & $7,837.1 \mathrm{f}$ \\
\hline $1393-1$ & D123E & 2.46 & $9.4 \mathrm{e}$ & $36.4 \mathrm{~d}$ & $67.6 \mathrm{f}$ & $97.1 \mathrm{ab}$ & $7,901.3 \mathrm{f}$ \\
\hline $1393-18$ & D123E & 3.13 & $7.3 \mathrm{f}$ & $22.3 \mathrm{e}$ & $59.0 \mathrm{~g}$ & $89.6 \mathrm{c}$ & $7,064.3 \mathrm{~g}$ \\
\hline $\mathrm{LSD}^{\mathrm{z}}$ & $\ldots$ & $\ldots$ & 3.3 & 4.9 & 2.5 & 3.2 & 112.1 \\
\hline
\end{tabular}

v Numbers followed by different lowercase letters are significantly different according to Fisher's protected least significant difference test at the $P=0.05$ level.

${ }^{w}$ Mutation presence conferring succinate dehydrogenase-inhibiting (SDHI) (D123E, H133R, H134R, and H278R) and quinone outside inhibitor (F129L) resistance.

${ }^{\mathrm{x}}$ Effective concentration at which the fungal growth is inhibited by $50 \%\left(\mathrm{EC}_{50}\right)$ values for fluopyram from in vitro assays.

y Area under dose response curve.

${ }^{\mathrm{z}}$ Least significant difference at the $P=0.05$ level. 
field trials in either year, their prevalence was high in plots receiving fluopyram in-furrow. As an explanation of this increased occurrence, it was initially thought that $A$. solani isolates possessing the $\mathrm{D} 123 \mathrm{E}$ mutation would have higher $\mathrm{EC}_{50}$ values for fluopyram in vitro and, therefore, reduced sensitivity to fluopyram. Although most isolates with the D123E mutation were determined to possess high levels of resistance to boscalid, all were determined to have low levels of insensitivity to fluopyram relative to baseline isolates. Furthermore, $20 \%$ of isolates with the D123E mutation were found to have $\mathrm{EC}_{50}$ values of $<5.0 \mu \mathrm{g} / \mathrm{ml}$ for boscalid, suggesting low levels of insensitivity to both fungicides. High levels of resistance to boscalid and low levels of insensitivity to fluopyram in A. solani isolates with the D123E mutation in vitro may be due to fluopyram having a slightly different binding site compared with other SDHI such as boscalid and penthiopyrad, rendering fluopyram activity unaffected by the same mutations (Avenot and Michailides 2010; Gudmestad et al. 2013; Miles et al. 2014).

Five D123E-mutant A. solani isolates, five SDHI-sensitive isolates, and five $A$. solani isolates possessing other mutations conferring SDHI resistance were chosen for in vivo studies based on $\mathrm{EC}_{50}$ values in vitro to both boscalid and fluopyram conveying low levels of insensitivity. Although all $15 \mathrm{~A}$. solani isolates chosen for greenhouse assessment possessed low $\mathrm{EC}_{50}$ values for boscalid and fluopyram in vitro, significant differences in disease control provided by both fungicides were observed in vivo. Percent disease control provided by boscalid was not significantly different among A. solani isolates possessing the D123E mutation and isolates possessing the H133R mutation but isolates possessing either of these mutations were controlled less with boscalid application compared with isolates possessing the H134R or H133R mutations, although not always significantly. This study suggested that $A$. solani isolates possessing either of these mutations may be associated with reduced disease control under boscalid, even though $\mathrm{EC}_{50}$ values in vitro suggest sensitivity to boscalid. Under the application of fluopyram, percent disease control was significantly lower for all D123E-mutant isolates compared with $A$. solani isolates possessing other SDHI mutations such as H133R, H134R, or H278R, regardless of similar $\mathrm{EC}_{50}$ values for fluopyram in vitro. It is apparent from the study reported here that, under in vivo conditions, isolates of $A$. solani with the D123E mutation are not controlled with either boscalid or fluopyram. Even A. solani isolates with extremely high sensitivity to fluopyram in vitro, such as isolates $1342-6$ and $1364-1\left(\mathrm{EC}_{50}=0.26\right.$ and 0.38 $\mu \mathrm{g} / \mathrm{ml}$, respectively), expressed significantly reduced disease control in vivo compared with isolates possessing the H134R, H133R, or H278R mutations and SDHI-sensitive isolates. This suggests that isolates with the D123E mutation have a selective advantage under selection pressure from fluopyram compared with SDHI-sensitive isolates and other SDHI-mutant isolates possessing the H278R, H134R, or H133R mutation, although it is unclear what that selective advantage might be.

Further evidence of this selective advantage was obtained from field trials in which $A$. solani isolates possessing the D123E mutation were recovered at significantly higher frequencies from treatments where fluopyram was applied in-furrow at planting in two separate years. Although disease severity among treatments receiving fluopyram in-furrow and treatments receiving foliar applications of fungicides was not significantly different either year, the genetic makeup of the isolates recovered from those treatments was different.
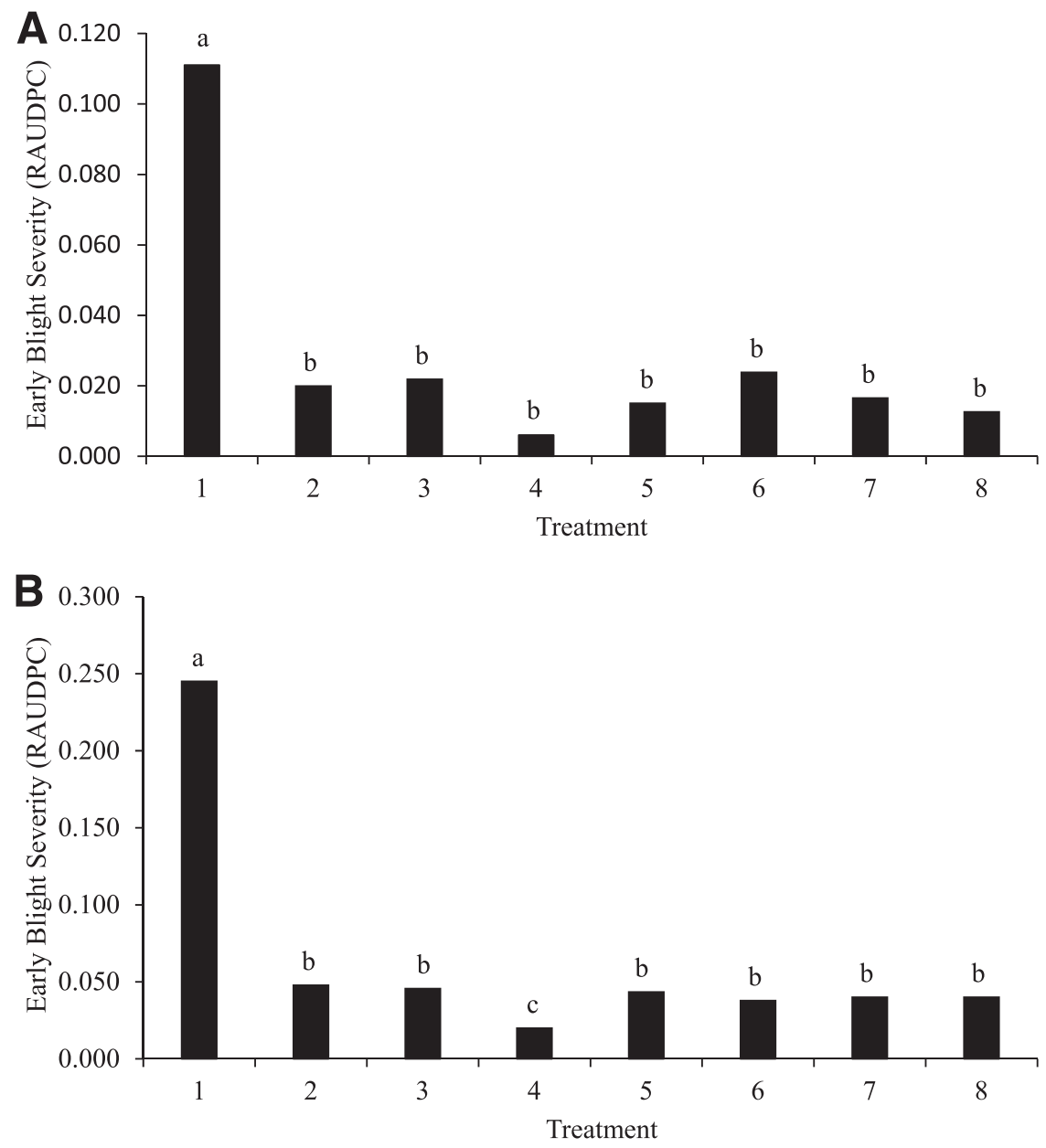

Fig. 3. Early blight severity expressed as relative area under the disease progress curve (RAUDPC) from a field trial conducted in A, 2013 and B, 2015 in Inkster, ND. Treatments included a nontreated control (bar 1); chlorothalonil (bar 2); mancozeb (bar 3); separate applications of quinone outside inhibitor, succinate dehydrogenase-inhibiting, and anilinopyrimidine fungicides, each mixed with standard protectants (bar 4); fluopyram in-furrow (bar 5); fluopyram in-furrow with a low and high rate of Bacillus subtilis (bars 6 and 7 , respectively); and imidacloprid in-furrow mixed with fluopyram and B. subtilis (bar 8). 
As previously discussed, none of the four isolates used in field inoculations possessed the D123E mutation, and none of the isolates collected from noninoculated plots or from plots receiving multiple applications of the standard protectants chlorothalonil and mancozeb were found to possess the D123E mutation in either year. However, 35 and $37.5 \%$ of isolates collected from plots receiving fluopyram alone in-furrow possessed the D123E mutation in 2013 and 2015, respectively, suggesting the existence of a selective advantage of A. solani isolates possessing the D123E mutation with a selection pressure of fluopyram under field conditions. Because fluopyram was registered in the United States in early 2012, very few studies have identified any resistance. However, Botrytis cinerea isolates possessing the $\mathrm{H} 272 \mathrm{Y}$ or $\mathrm{H} 272 \mathrm{~L}$ mutation in the $B c S d h B$ gene recovered from strawberry were shown to have reduced sensitivity to the chemistry (Amiri et al. 2014). Low and moderate levels of resistance to fluopyram have also been detected in A. alternata isolates collected from peach orchards in South Carolina (Yang et al. 2015). Given the ability of A. solani to develop resistance to QoI, SDHI, and AP fungicides (Fairchild et al. 2013; Fonseka and Gudmestad 2016; Gudmestad et al. 2013; Pasche et al. 2004, 2005), it is highly probable that resistance to fluopyram will further develop and be characterized beyond the selective advantage reported here. The application of fluopyram in-furrow, while initially providing excellent season-long early blight control, places constant selection pressure upon the $A$. solani population due to the systemic activity of the fungicide. Fluopyram has been previously determined to be highly xylem systemic when applied in-furrow and translocated to the growing point of the plant (Laleve et al. 2013), possibly due to high water solubility that is favorable for translocation (Labourdette et al. 2011).

Perhaps the most interesting outcome of these studies is that $A$. solani isolates with the D123E mutation were recovered at significantly lower frequencies from plots receiving Bacillus subtilis (Serenade Soil) mixed with fluopyram in-furrow in field trails compared with fluopyram applied alone in-furrow. Although the frequency of isolates possessing the D123E mutation was significantly higher in all plots where fluopyram was applied in-furrow compared with other treatments, results suggest that $B$. subtilis may have suppressive activity against $A$. solani isolates possessing the D123E mutation. Furthermore, a significantly lower frequency of $A$. solani isolates with the D123E mutation was detected in plots receiving a higher rate of $B$. subtilis mixed with

Table 6. Frequency of Alternaria solani isolates with mutations conferring resistance to succinate dehydrogenase inhibiting (SDHI) fungicides collected from treatments in two separate years ${ }^{y}$

\begin{tabular}{cllllll}
\hline $\begin{array}{l}\text { Year, } \\
\text { treatment }\end{array}$ & H278Y & H278R & H134R & H133R & $\begin{array}{c}\text { Wild } \\
\text { type }\end{array}$ & D123E \\
\hline 2013 & & & & & & \\
1 & $42.5 \mathrm{ab}$ & $0.0 \mathrm{~b}$ & $18.1 \mathrm{c}$ & $12.5 \mathrm{a}$ & $27.5 \mathrm{a}$ & $0.0 \mathrm{c}$ \\
2 & $37.5 \mathrm{bcd}$ & $2.5 \mathrm{ab}$ & $50.0 \mathrm{~b}$ & $5.0 \mathrm{~b}$ & $5.0 \mathrm{~cd}$ & $0.0 \mathrm{c}$ \\
3 & $35.0 \mathrm{cde}$ & $5.0 \mathrm{a}$ & $55.0 \mathrm{~b}$ & $0.0 \mathrm{~b}$ & $5.0 \mathrm{~cd}$ & $0.0 \mathrm{c}$ \\
4 & $12.0 \mathrm{f}$ & $3.1 \mathrm{ab}$ & $81.2 \mathrm{a}$ & $3.1 \mathrm{~b}$ & $0.0 \mathrm{~d}$ & $0.0 \mathrm{c}$ \\
5 & $32.0 \mathrm{de}$ & $5.0 \mathrm{a}$ & $6.2 \mathrm{~d}$ & $11.8 \mathrm{a}$ & $10.0 \mathrm{bc}$ & $35.0 \mathrm{a}$ \\
6 & $40.0 \mathrm{abc}$ & $0.0 \mathrm{ab}$ & $20.0 \mathrm{c}$ & $5.0 \mathrm{~b}$ & $15.0 \mathrm{~b}$ & $20.0 \mathrm{~b}$ \\
7 & $45.0 \mathrm{a}$ & $0.0 \mathrm{~b}$ & $50.0 \mathrm{~b}$ & $0.0 \mathrm{~b}$ & $5.0 \mathrm{~cd}$ & $0.0 \mathrm{c}$ \\
8 & $30.0 \mathrm{e}$ & $0.0 \mathrm{~b}$ & $54.4 \mathrm{~b}$ & $4.4 \mathrm{~b}$ & $0.0 \mathrm{~d}$ & $12.5 \mathrm{~b}$ \\
2015 & & & & & & \\
1 & $50.0 \mathrm{a}$ & $0.0 \mathrm{~b}$ & $25.0 \mathrm{~d}$ & $10.0 \mathrm{a}$ & $15.0 \mathrm{a}$ & $0.0 \mathrm{~d}$ \\
2 & $40.0 \mathrm{bc}$ & $0.0 \mathrm{~b}$ & $55.0 \mathrm{bc}$ & $5.0 \mathrm{ab}$ & $0.0 \mathrm{~b}$ & $0.0 \mathrm{~d}$ \\
3 & $30.0 \mathrm{~d}$ & $5.0 \mathrm{a}$ & $65.0 \mathrm{~b}$ & $0.0 \mathrm{~b}$ & $0.0 \mathrm{~b}$ & $0.0 \mathrm{~d}$ \\
4 & $10.0 \mathrm{e}$ & $2.5 \mathrm{ab}$ & $80.0 \mathrm{a}$ & $5.0 \mathrm{ab}$ & $0.0 \mathrm{~b}$ & $2.5 \mathrm{~cd}$ \\
5 & $30.0 \mathrm{~d}$ & $0.0 \mathrm{~b}$ & $27.5 \mathrm{~d}$ & $5.0 \mathrm{ab}$ & $0.0 \mathrm{~b}$ & $37.5 \mathrm{a}$ \\
6 & $45.0 \mathrm{ab}$ & $5.6 \mathrm{a}$ & $25.0 \mathrm{~d}$ & $10.0 \mathrm{a}$ & $0.0 \mathrm{~b}$ & $15.0 \mathrm{~b}$ \\
7 & $40.0 \mathrm{bc}$ & $0.0 \mathrm{~b}$ & $50.0 \mathrm{c}$ & $5.0 \mathrm{ab}$ & $0.0 \mathrm{~b}$ & $5.0 \mathrm{~cd}$ \\
8 & $35.0 \mathrm{~cd}$ & $0.0 \mathrm{~b}$ & $55.0 \mathrm{bc}$ & $0.0 \mathrm{~b}$ & $0.0 \mathrm{~b}$ & $10.0 \mathrm{bc}$ \\
\hline
\end{tabular}

${ }^{y}$ Numbers followed by different lowercase letters are significantly different according to Fisher's protected least significant difference test at the $P=0.05$ level.

${ }^{\mathrm{z}}$ Treatments included a nontreated control (1); chlorothalonil (2); mancozeb (3); separate applications of quinone outside inhibitor, SDHI, and anilino-pyrimidine fungicides, each mixed with standard protectants (4); fluopyram in-furrow (5); fluopyram in-furrow with a low and high rate of Bacillus subtilis ( 6 and 7 , respectively); and imidacloprid in-furrow mixed with fluopyram and $B$. subtilis (8). fluopyram compared with a lower rate of $B$. subtilis applied with fluopyram in-furrow. $B$. subtilis is a biofungicide that is available in a wettable powder or aqueous suspension formulation for use on various crops to control foliar diseases, including gray mold (Botrytis cinerea), fire blight (Erwinia amylovora), white mold (Sclerotinia sclerotiorum), and early blight (A. solani) (Abbasi and Weselowski 2015). In some cases, Bacillus subtilis can trigger an enhanced state of resistance in plants known as systemic acquired resistance (SAR) associated with the accumulation of salicylic acid (Métrauxs 2001) and pathogenesisrelated (PR) proteins (Van Loon and Van Strien 1999). The ability of B. subtilis to reduce disease incidence caused by Colletotrichum lagenarium and Pythium aphanidermatum by inducing a SAR defense response in cucumber and tomato plants determined that PR proteins associated with SAR were expressed to higher levels in inoculated plants receiving applications of $B$. subtilis (Ongena et al. 2005). Further studies will be needed to determine the effect of $B$. subtilis on early blight disease control but one hypothesis may be that the application of $B$. subtilis applied in a mixture with fungicides provides activity against $A$. solani isolates possessing the D123E mutation by inducing $\mathrm{SAR}$ in potato plants and increasing the expression of $\mathrm{PR}$ proteins.

One of the most important factors to consider in the development of fungicide resistance is the parasitic fitness of resistant isolates in the presence and absence of selection pressure (Dekker 1976). Fitness can be defined as the survival or reproductive success of an allele, individual, or group (Pringle and Taylor 2002) and, if a resistant subpopulation of a pathogen is more prevalent, fitness costs may be absent and differences in parasitic fitness between fungicide-resistant and -sensitive isolates may exist (Fan et al. 2015). One reason for the observed selection advantage of $A$. solani isolates possessing the D123E mutation under fluopyram in this study may be increased parasitic fitness of D123E-mutant isolates under selection pressure. A selective disadvantage or reduced fitness of A. alternata isolates that possess the D123E mutation on the $A a S d h D$ gene has previously been speculated because isolates with this mutation were recovered at very low frequencies (Avenot and Michailides 2010; Avenot et al. 2009). Although initially recovered at very low frequencies in previous studies (Mallik et al. 2014), the increased frequency of $A$. solani isolates possessing the D123E mutation may suggest the absence of fitness penalties in these isolates. Although A. solani isolates possessing the F129L mutation conferring resistance to QoI fungicides were previously reported to have reduced spore germination in vitro compared with wild-type isolates, the same study also determined that isolates with the F129L mutation had increased aggressiveness in vivo, indicating the absence of any substantial fitness penalties (Pasche and Gudmestad 2008). Similarly, no evidence of major fitness penalties due to mutations in the $S d h B$ gene in SDHI-resistant Botrytis cinerea isolates recovered from strawberry were identified (Amiri et al. 2014). Other research has reported increased sensitivity to oxidative stress in A. alternata isolates possessing mutations conferring SDHI resistance, including isolates possessing the D123E mutation (Avenot et al. 2009; Fan et al. 2015), but no significant fitness penalties, suggesting that resistant isolates would likely compete successfully under field conditions. However, nothing is known about the fitness of $A$. solani isolates possessing the D123E mutation in the absence of selection pressure and future research will focus on the characterization of any fitness penalties associated with mutations conferring SDHI resistance.

This report clearly demonstrates that $A$. solani isolates possessing the D123E mutation have a selective advantage under the application of fluopyram compared with wild-type $A$. solani isolates and isolates possessing other mutations conferring SDHI resistance such as the H278R, H134R, and H133R. In the studies reported here, we demonstrated the lack of disease control of A. solani isolates with the D123E mutation under the application of fluopyram in vivo and identified a significantly higher prevalence of isolates possessing the D123E mutation in treatments receiving fluopyram in-furrow at planting in the field. These data suggest that applying fluopyram in-furrow for early blight control in commercial potato fields could lead to the further increase of D123E-mutant A. solani isolates and, in turn, lead to reduced disease control. Future research will need to evaluate the fitness of 
A. solani isolates possessing mutations conferring SDHI resistance in the absence of fungicide selection pressure. Furthermore, because reduced sensitivity of $A$. solani to pyrimethanil was detected in field isolates collected in 2010 from Idaho (Fairchild et al. 2013) and further studies have shown reduced sensitivity to pyrimethanil in vivo (Fonseka and Gudmestad 2016), monitoring for and assessing the fitness of A. solani isolates resistant to three chemical classes will be important to assess the impact that fungicide resistance in A. solani will have on the future of successful control of early blight disease of potato.

\section{Acknowledgments}

We thank I. Mallik, D. Peterson, and R. Benz for providing technical support.

\section{Literature Cited}

Abbasi, P. A., and Weselowski, B. 2015. Efficacy of Bacillus subtilis QST 713 formulations, copper hydroxide, and their tank mixes on bacterial spot of tomato. Crop Prot. 74:70-76.

Amiri, A., Brannen, P. M., and Schnabel, G. 2010. Reduced sensitivity in Monilinia fructicola field isolates from South Carolina and Georgia to respiration inhibitor fungicides. Plant Dis. 94:737-743.

Amiri, A., Heath, S. M., and Peres, N. A. 2014. Resistance to fluopyram, fluxapyroxad, and penthiopyrad in Botrytis cinerea from strawberry. Plant Dis. 98:532-539

Avenot, H. F., and Michailides, T. J. 2007. Resistance to boscalid fungicide in Alternaria alternata isolates from pistachio in California. Plant Dis. 91:1345-1350.

Avenot, H. F., and Michailides, T. J. 2010. Progress in understanding molecular mechanisms and evolution of resistance to succinate dehydrogenase inhibiting (SDHI) fungicides in phytopathogenic fungi. Crop Prot. 29:643-651.

Avenot, H. F., Sellam, A., and Michailides, T. J. 2009. Characterization of mutations in the membrane-anchored subunits AaSDHC and AaSDHD of succinate dehydrogenase from Alternaria alternata isolates conferring field resistance to the fungicide boscalid. Plant Pathol. 58:1134-1143.

Avenot, H. F., Thomas, A., Gitaitis, R. D., Langston, D. B., Jr., and Stevenson, K. 2012. Molecular characterization of boscalid- and penthiopyrad-resistant isolates of Didymella bryoniae and assessment of their sensitivity to fluopyram. Pest Manage. Sci. 68:645-651.

Bardas, G. A., Veloukas, T., Koutita, O., and Karaoglanidis, G. S. 2010. Multiple resistance of Botrytis cinerea from kiwifruit to SDHIs, QoIs and fungicides of other chemical groups. Pest Manage. Sci. 66:967-973.

Bauske, M. J., Mallik, I., Yellareddygari, S. K. R., and Gudmestad, N. C. 2018. Spatial and temporal distribution of mutations conferring QoI and SDHI resistance in Alternaria solani across the United States. Plant Dis. 102:349-358.

Dekker, J. 1976. Acquired resistance to fungicides. Annu. Rev. Phytopathol. 14: 405-428.

Fairchild, K. L., Miles, T. D., and Wharton, P. S. 2013. Assessing fungicide resistance in populations of Alternaria in Idaho potato fields. Crop Prot. 49:31-39.

Fan, Z., Yang, J.-H., Fan, F., Luo, C.-X., and Schnabel, G. 2015. Fitness and competitive ability of Alternaria alternata field isolates with resistance to SDHI, QoI, and MBC fungicides. Plant Dis. 99:1744-1750.

Fonseka, D. L., and Gudmestad, N. C. 2016. Spatial and temporal sensitivity of Alternaria species associated with potato foliar diseases to demethylation inhibiting and anilino-pyrimidine fungicides. Plant Dis. 100:1848-1857.

Gudmestad, N. C., Arabiat, S., Miller, J. S., and Pasche, J. S. 2013. Prevalence and impact of SDHI fungicide resistance in Alternaria solani. Plant Dis. 97:952-960.

Holm, A. L., Rivera, V. V., Secor, G. A., and Gudmestad, N. C. 2003. Temporal sensitivity of Alternaria solani to foliar fungicides. Am. J. Potato Res. 80:33-40.

Ishii, H., Miyamoto, T., Ushio, S., and Kakishima, M. 2011. Lack of cross resistance to a novel succinate dehydrogenase inhibitor, fluopyram, in highly boscalid-resistant isolates of Corynespora cassiicola and Podosphaera xanthii. Pest Manage. Sci. 67:474-482.

Labourdette, G., Lachaise, H., Rieck, H., and Steiger, D. 2011. Fluopyram: Efficacy and beyond on problematic diseases. Pages 75-80 in: Modern Fungicides and Antifungal Compounds, Vol. VI. H. W. Dehne, H. B. Deising, U. Gisi, K. H. Kuck, P. E. Russell, and H. Lyr, eds. DPG, Braunschweig, Germany.

Laleve, A., Walker, A.-S., Gamer, S., Toquin, V., Debieu, D., and Fillinger, S. 2013. From enzyme to fungal development or how SdhB mutations impact respiration, fungicide resistance and fitness in the grey mold agent Botrytis cinerea. Page 80 in: (Abstr.) Modern Fungicides and Antifungal Compounds17th Int. Reinhardsbrunn Symp. Friedricroda, Germany.
Leroch, M., Kretschmer, M., and Hahn, M. 2011. Fungicide resistance phenotypes of Botrytis cinerea isolates from commercial vineyards in South West Germany. J. Phytopathol. 159:63-65.

Mallik, I., Arabiat, S., Pasche, J. S., Bolton, M. D., Patel, J. S., and Gudmestad, N. C. 2014. Molecular characterization and detection of mutations associated with resistance to succinate dehydrogenase-inhibiting fungicides in Alternaria solani. Phytopathology 104:40-49.

Métrauxs, J. P. 2001. Systemic acquired resistance and salicylic acid: Current state of knowledge. Eur. J. Plant Pathol. 107:13-18.

Miles, T. D., Miles, L. A., Fairchild, K. L., and Wharton, P. S. 2014. Screening and characterization of resistance to succinate dehydrogenase inhibitors in Alternaria solani. Plant Pathol. 63:155-164.

Milliken, G. A., and Johnson, D. E. 1992. One-way treatment structure in a completely randomized design with heterogeneous errors. Pages 16-28 in: Analysis of Messy Data. Vol. I. Designed Experiments. Chapman and Hall, London.

Miyamoto, T., Ishii, H., Seko, T., Kobori, S., and Tomita, Y. 2009. Occurrence of Corynespora cassiicola isolates resistant to boscalid on cucumber in Ibaraki Prefecture, Japan. Plant Pathol. 58:1144-1151.

Myresiotis, C. K., Bardas, G. A., and Karaglanidis, G. S. 2008. Baseline sensitivity of Botrytis cinerea to pyraclostrobin and boscalid and control of anilinopyrimdineand benzimidazole-resistant strains by these fungicides. Plant Dis. 92: 1427-1431.

Nnodu, E. C., Harrison, M. D., and Parke, R. V. 1982. The effect of temperature and relative humidity on wound healing and infection of potato tubers by Alternaria solani. Am. Potato J. 59:297-311.

Ongena, M., Duby, F., Jourdan, E., Beaudry, T., Jadin, V., Dommes, J., and Thonart, P. 2005. Bacillus subtilis M4 decreases plant susceptibility towards fungal pathogens by increasing host resistance associated with differential gene expression. Appl. Microbiol. Biotechnol. 67:692-698.

Pasche, J. S., and Gudmestad, N. C. 2008. Prevalence, competitive fitness and impact of the F129L mutation in Alternaria solani in the United States. Crop Prot. 27:427-435

Pasche, J. S., Piche, L. M., and Gudmestad, N. C. 2005. Effect of the F129L mutation in Alternaria solani on fungicides affecting mitochondrial respiration. Plant Dis. 89:269-278

Pasche, J. S., Wharam, C., and Gudmestad, N. C. 2004. Shift in sensitivity of Alternaria solani in response to QoI fungicides. Plant Dis. 88:181-187.

Pringle, A., and Taylor, J. W. 2002. The fitness of filamentous fungi. Trends Microbiol. 10:474-481.

Rotem, J. 1994. The Genus Alternaria: Biology, Epidemiology, and Pathogenicity. American Phytopathological Society, St. Paul, MN.

Shaner, G., and Finney, R. E. 1977. The effect of nitrogen fertilization on the expression of slow-mildewing resistance in Knox wheat. Phytopathology 67: $1051-1056$

Sierotzki, H., and Scalliet, G. 2013. A review of current knowledge of resistance aspects for the next generation succinate dehydrogenase inhibitor fungicides. Phytopathology 103:880-887.

Stewart, C., and Via, L. E. 1999. A rapid CTAB DNA isolation technique useful for RAPD fingerprinting and other PCR applications. BioTechniques 14: 748-749.

Toffolatti, S. L., Venturini, G., and Bianco, P. A. 2016. First report of SDHI resistant strains of Venturia inaequalis from commercial orchards in Northern Italy. Plant Dis. 100:2324.

Van Loon, L. C., and Van Strien, E. A. 1999. The families of pathogenesis-related proteins, their activities, and comparative analysis of PR-1 type proteins. Physiol. Mol. Plant Pathol. 55:85-97.

Wharton, P., Fairchild, K., Belcher, A., and Wood, E. 2012. First report of in-vitro boscalid-resistant isolates of Alternaria solani causing early blight of potato in Idaho. Plant Dis. 96:454

Wong, F. P., and Wilcox, W. F. 2002. Sensitivity to azoxystrobin among isolates of Uncinula necator: Baseline distribution and relationship to myclobutanil sensitivity. Plant Dis. 86:394-404.

Yang, J. H., Brannen, P. M., and Schnabel, G. 2015. Resistance in Alternaria alternata to SDHI fungicides causes rare disease outbreak in peach orchards. Plant Dis. 99:65-70.

Yellareddygari, S. K. R., Pasche, J. S., Taylor, R. J., and Gudmestad, N. C. 2016. Individual participant data meta-analysis comparison of foliar fungicides applied for potato early blight management. Plant Dis. 100:200-206.

Yin, Y. N., Kim, Y. K., and Xiao, C. L. 2011. Molecular characterization of boscalid resistance in field isolates of Botrytis cinerea from apple. Phytopathology 101:986-995. 